\title{
Decreased serum and mucosa immunoglobulin A levels in vitamin A- and zinc-deficient mice
}

\author{
SORAYYA KHEIROURI, MOHAMMAD ALIZADEH
}

Department of Nutrition, Tabriz University of Medical Sciences, Tabriz, Iran

\begin{abstract}
Simultaneous zinc and vitamin A deficiency are common health problems in developing countries. The objective of this study was to assess the effect of vitamin A-and zinc-deficient diet on immunoglobulin A (IgA) response. Six-week-old mice were assigned into two groups receiving a normal vitamin $A$ and zinc or low vitamin A and zinc diet for five months. Serum and intestinal mucosa IgA levels were determined by the enzyme-linked immunosorbent assay method. The concentration of zinc in serum was determined using an inductively coupled plasma mass spectrometer. Vitamin A measurement in serum was carried out by high performance liquid chromatography. Mice maintained on a low vitamin A and zinc diet showed significantly greater food intake but lower production of IgA both in serum and mucosa. A mucosa IgA level was significantly higher in both control and deficient groups than the serum IgA level. Results indicated that zinc and vitamin A deficiency is associated with a lower production of IgA. Micronutrient intervention strategies addressing IgA-related gastrointestinal infections are needed.
\end{abstract}

Key words: zinc, vitamin A, IgA.

(Centr Eur J Immunol 2014; 39 (2): 165-169)

\section{Introduction}

Immunoglobulin A ( $\operatorname{Ig} \mathrm{A})$, the most abundant immunoglobulin isotype in the body, exists in two isotypes, circulating monomeric $\operatorname{IgA}(\operatorname{IgA} 1)$ and secretory polymeric $\operatorname{IgA}(\operatorname{IgA} 2)$. IgA1 predominates in serum $(\sim 80 \%)$, whereas $\operatorname{IgA} 2$, called secretory $\operatorname{IgA}(\operatorname{sg} \mathrm{A})$, is the main immunoglobulin found in mucous secretions including the gastrointestinal tract, which plays a critical role in mucosal immunity $[1,2]$. Secretory IgA has long been recognized as a first line of defense in mucosal secretions of the respiratory tract, gastrointestinal and genitourinary system. Although the exact role of $\operatorname{IgA}$ in a cluster of systemic immune responsiveness to exogenous and endogenous antigenic components have not been fully clarified, decreased or absent IgA has been considered as a clinically significant immunodeficiency [3, 4]. Most of IgA-deficient individuals appear to be clinically asymptomatic. However, a common problem in IgA deficiency is susceptibility to infections with the incidence of recurrent mucosal infectious diseases. In patients with selective IgA deficiency, recurrent otitis, upper respiratory tract infections and pneumonia are the most common infections [5]. Gastrointestinal infections and chronic diarrhea have been seen in some patients $[5,6]$.
Primary $\operatorname{Ig}$ A deficiency is the most frequent immunoglobulin deficiency syndrome. From the epidemiological point of view, there is a wide variation in prevalence of disease. The lowest prevalence has been reported in East Asian countries while the highest frequency has been observed in Caucasians which is around one in 500 [7]. Although no clear speculation has been proposed for this wide global distribution of the disease, ethnic background has been proposed as one of the influential factors. Also, it has been suggested that regulatory signaling of mucosal immunity is strongly correlated with nutritional factors such as lipids, proteins, and micro and trace nutrients, which are critical cofactors for these signaling pathways [8-10]. It has been well documented that many nutrients specifically affect many aspects of the metabolic process which result in proper or improper shaping of both local and systemic immune responses [11].

Zinc and vitamin A are two nutritional factors that modulate many immune responses by regulating antibody synthesis and secretion $[12,13]$. They also indirectly help body surface defenses by improving maintenance of mucosal surfaces [14]. There is accumulative epidemiological evidence on concurrent deficiencies of vitamin A and zinc in many communities [15-17] where susceptibility of infants and children to gastrointestinal infections is prevalent

Correspondence: Mohammad Alizadeh MD, PhD, Department of Nutrition, Tabriz University of Medical Sciences. Tabriz, Iran, e-mail: malizadeh@tbzmed.ac.ir 
$[18,19]$. This is partly due to many metabolic interactions between zinc and vitamin A [20]. Besides, both nutrients are known to play a substantial role in the maintenance of gastrointestinal epithelium [21, 22]. Therefore, it is hypothesized that IgA production may be influenced by deficiencies of the nutrients. This paper aims to examine the association between dietary intake of zinc and vitamin A with the serum and mucosal level of $\operatorname{IgA}$ in an animal model.

\section{Material and methods}

\section{Animals and husbandry}

A well-controlled light-dark cycle, air temperature (20$22^{\circ} \mathrm{C}$ ) and relative humidity of $50-60 \%$ were maintained in the animal keeping laboratory. All animals had free access to semi-purified experimental diet and distilled water throughout the experiment. The food was prepared every day roughly as dough pellets. Food intake was determined daily and body weights were recorded twice per week.

\section{Experimental design and diets}

Young adult, male, pathogen-free, ddY mice $(N=11$, average weight 27-29 g) and aged 6 weeks were assigned into two control and deficient groups. The control group $(n=6)$ were fed a normal diet containing sufficient retinyl acetate, as vitamin A, and zinc (5000 IU vitamin A/kg, 60.2 $\mathrm{mg}$ zinc $/ \mathrm{kg})$ and the deficient group $(n=5)$ maintained on a low vitamin A and zinc (550 IU vitamin A/kg supplemented in the form of retinyl acetate, $5.2 \mathrm{mg}$ zinc $/ \mathrm{kg}$ ) diet, as the experimental group, for a period of five months. There was no difference in lipid, carbohydrate and protein content of the diets of groups. Also, mineral and vitamin content of diets was kept constant except for vitamin A and zinc as mentioned above. The diet contained per 100 gram: Casein: 20, Sugar: 22.4, $\alpha$-Corn starch: 44.6, Soybean oil: 5, Cellulose: 2, Mineral mixture: 5 and Vitamin mixture: 1. Composition of the mineral mixture was as follows: $\mathrm{CaH}-$ $\mathrm{PO}_{4}: 14.56, \mathrm{NaCl}: 4.66$, Fe-citrate: $3.18, \mathrm{MgSO}_{4}: 7.17$, $\mathrm{MnSO}_{4}: 0.12, \mathrm{CuSO}_{4}: 0.03, \mathrm{KI}: 0.01 \mathrm{~g} / 100 \mathrm{~g}$ of mixture. The vitamin mixture contained vitamin $\mathrm{D}_{3}: 0.25 \mathrm{mg}$, vitamin $\mathrm{E}$ acetate: $500 \mathrm{mg}$, vitamin $\mathrm{K}_{3}: 520 \mathrm{mg}$, vitamin $\mathrm{B}$ complex: 2.2 gram, vitamin C: $3 \mathrm{~g}$ and inositol: $600 \mathrm{mg}$ per $100 \mathrm{~g}$. The mineral and vitamin mixture were free of zinc and vitamin A, respectively. Zinc contamination was avoided by using deionized water and wearing polyethylene gloves for the preparation of animals' diet.

\section{Blood collection}

At the end of the experiment, mice were killed under deep anesthesia with Nembutal (Dainippon Pharmaceutical Co., Ltd., Japan). The blood collected via cardiac puncture and sera was immediately collected after centrifugation at $5000 \mathrm{~g}$ and stored in $-20^{\circ} \mathrm{C}$ until used.

\section{Preparation of intestinal mucosa extracts}

Segments of jejunum intestine were precisely removed from the nearly $2 \mathrm{~cm}$ after stomach to the ileocecal valve. Mucosal piles were immediately weighed and maintained in $1 \mathrm{ml}$ of cold phosphate buffer saline (PBS) and homogenized with a digital Teflon homogenizer (AS ONE, model: AN, Japan) for 1 minute at $4000 \mathrm{~g}$. After centrifugation for 20 minutes at $4^{\circ} \mathrm{C}$ with the speed of $13500 \mathrm{~g}$, supernatants were used for IgA assessments.

\section{Determination of serum and intestinal mucosa total immunoglobulin A}

Serum and intestinal mucosa total IgA levels were determined by enzyme-linked immunosorbent assay (ELISA) method using a mouse IgA ELISA quantitation kit (Bethyl Laboratories, Inc, TX, U.S.A) according to the manufacturer's instructions. In brief, goat anti-mouse IgA-affinity purified antibody was dispensed in each well and incubated for an hour at room temperature. They were then washed with a wash solution containing $50 \mathrm{mM}$ Tris, $0.14 \mathrm{M} \mathrm{NaCl}, 0.05 \%$ Tween 20 for three times. After blocking non specific binding sites and incubating for 30 minutes at room temperature, standards and samples were added and incubated for $60 \mathrm{~min}-$ utes at room temperature. Horseradish peroxidase-conjugated Goat anti-mouse IgA was added to each well and incubated for $60 \mathrm{~min}$ at room temperature. Finally, after addition of an appropriate substrate, absorbance was read with ELISA reader (Corona Electric, MTP-32, Japan) at $450 \mathrm{~nm}$.

\section{Determination of serum zinc and retinol}

The concentration of zinc in serum was determined using an inductively coupled plasma mass spectrometer (ICP-MS; model 8500, Shimadzu, Tokyo, Japan) as previously described [23]. Vitamin A measurement in serum was carried out by high performance liquid chromatography (HPLC) according to a method described previously [24] using a HPLC system (Shiseido Co. Ltd, Tokyo, Japan).

\section{Statistics}

Data were first checked for distribution using Kolmogorov-Smirnov test. Statistical analysis was done using independent sample $t$-test. The data were analyzed using SPSS (version 11.5) and expressed as mean \pm SD and considered significant at $p<0.05$.

\section{Results}

\section{Animal growth and food intake}

As shown in Fig. 1, there were no significant differences in final body weights among two groups. Animals kept on a low vitamin A and zinc diet (deficient group) had significantly more $(p<0.05)$ food intake as compared to the controls. 

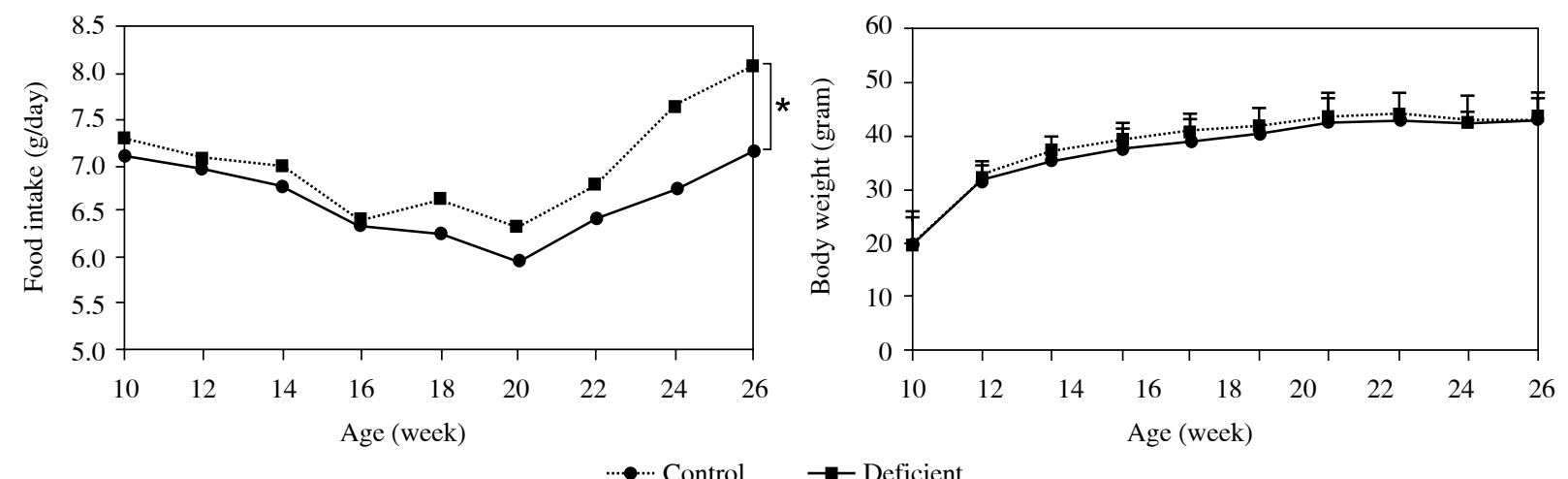

Fig. 1. Mean \pm SD of food intake and body weight of control (normal zinc and vitamin $A$ ) and deficient groups (low vitamin A and zinc). A single asterisk represents $p<0.05$

\section{Serum and mucosal immunoglobulin A}

As shown in Fig. 2, serum level of IgA significantly decreased in animals with a low vitamin A and zinc diet as compared to the control group. A remarkable reduction of mucosal IgA was observed in the deficient group as compared to the control group.

Mucosa IgA levels were significantly greater (1.5 fold) either in control or deficient groups as compared to serum levels.

\section{Levels of zinc and vitamin $A$ in serum}

As shown in Fig. 3, serum zinc concentration significantly decreased $(p<0.05)$ in animals kept on a zinc and vitamin A deficient diet compared to those fed normal diet. Also, serum retinol concentration decreased remarkably $(p=0.05)$ in the deficient group as compared to the control group.

A

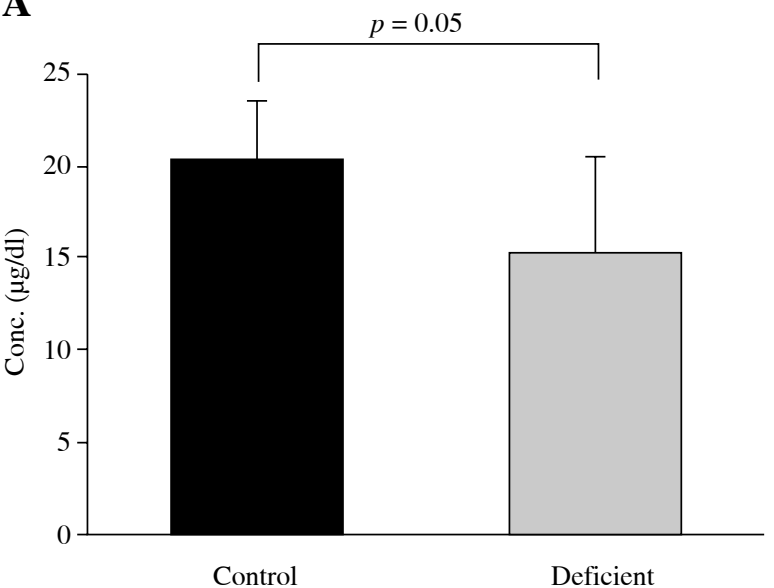

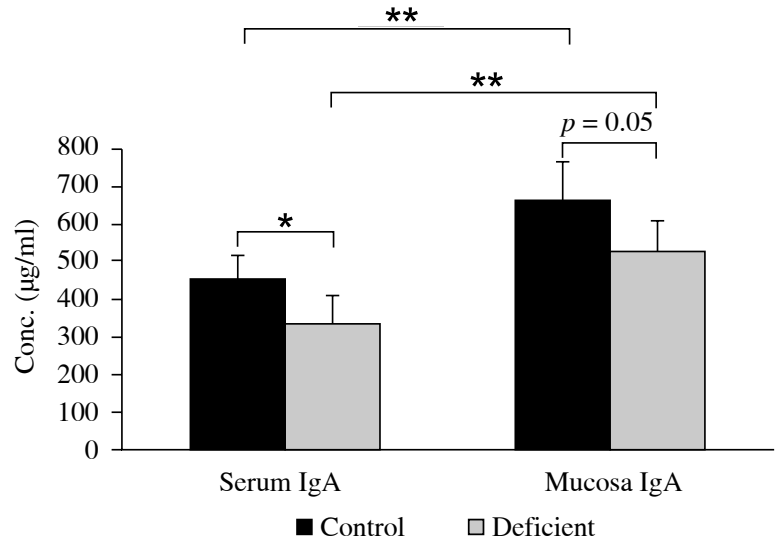

Fig. 2. Mean \pm SD of IgA secreted by control (normal zinc and vitamin A) and deficient groups (low vitamin A and zinc). Single and double asterisks represent $p<0.05$ and $p<0.01$, respectively

B

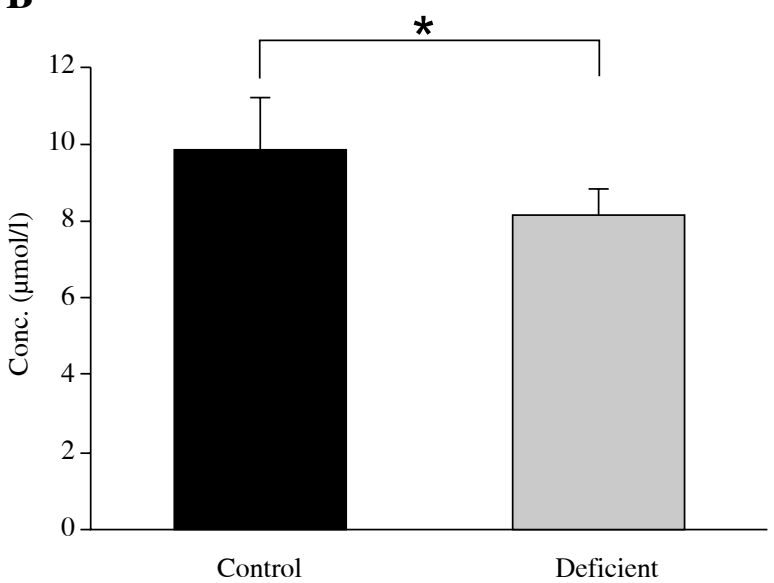

Fig. 3. Mean \pm SD of A) serum retinol and B) serum zinc concentration by control (normal zinc and vitamin A) and deficient groups (low vitamin A and zinc). Single asterisk represents $p<0.05$ 


\section{Discussion}

The results of decades of work indicate that zinc and vitamin A deficiencies affect multiple aspects of innate and adaptive immunity. Zinc functions as an intracellular signal molecule for immune cells [25] and regulates generation of cytokines [26], several functions of lymphocytes [4], activation of T cells and natural killer cells, and more specifically cellular immunity [6]. In addition, zinc deficiency in humans may result in thymic atrophy and lymphopenia, which in turn hampers both cellular and humeral branches of immune response [27, 28]. Similar findings are evident on the effect of vitamin A deficiency on the ability of individual's immune system to counteract pathogens. Moreover, this micronutrient is known to regulate antibody production via many pro and anti inflammatory modulators [29].

Mice fed the deficient diet revealed some clinical symptoms such as irritability and hair loss which was then replaced with sparse and coarse hair. The signs have been attributed to zinc deficiency (ZD) in previous studies [30] and represent that the deficient model has been established.

Mice receiving a low zinc and vitamin A diet showed a higher food intake with no difference in body weight as compared to the control group. Earlier investigations have defined anorexia as important signs for ZD [30, 31] and reported less food intake, poor body weight gain for zinc-deficient animals [30, 32]. However, anorexia which leads to failure in body weight gain has not been observed in mild to moderate ZD. In the present study, strict ZD could not been induced because casein used as source of protein contained at least $5.2 \mathrm{mg}$ of zinc per $\mathrm{kg}$ of the diet. Some studies have shown that animals fed a low vitamin A diet had a significant reduction in body weight [33-35] and some others reported that vitamin A deficiency (VAD) did not influence longitudinal growth in mice [36, 37]. Several studies have also demonstrated that vitamin A-deficient rats had a significantly decreased food intake [35, 37]. On the other hand, it has been reported that mild to moderate zinc and vitamin A deprivation frequently produces an increased food intake to compensate for a decreased food efficiency $[38,39]$ which is in good agreement with our observations.

Immunoglobulin A plays a critical role in mucosal immunity. The intestine is one of the tissues most sensitive to ZD and more susceptible to the effects of VAD. In the present study, we found a markedly reduced IgA level both in serum and mucosa of animals kept on a deficient diet. Flattening of villi, decreased numbers of crypts, inflammatory cell infiltration of the lamina propria and lesions of intestinal mucosa have been reported in both experimental animal and human ZD [40-42]. Nevertheless, to our best knowledge, there is no report to address effects of $\mathrm{ZD}$ on IgA production. On the other hand, vitamin A is known to be an important regulator for proliferation of epithelial cells [43]. Accumulative reports are available showing that VAD results in reduction of IgA production [44, 45]. Therefore, the observed finding in the present study might be attributing to lack of vitamin A in the animals' diet.

It was observed that intestinal mucosa IgA titer was greater by almost 1.5 fold than serum IgA. It has long been known that the mucosal immune system contains more than $80 \%$ of all Ig-producing cells in the body, and the major product of these cells in normal individuals is $\operatorname{IgA~[46].~}$ More IgA is produced in mucosal linings than all other types of antibody combined [47]. It has been estimated that every day three to five grams are secreted into the intestinal lumen [48]. It is worth noting that this accounts for $15 \%$ of the total immunoglobulin produced in the entire body $[49,50]$.

In summary, our findings indicate that concurrent deficiency of zinc and vitamin A suppresses production of $\operatorname{IgA}$ and also intestinal mucosa $\operatorname{IgA}$ production is greater than serum which may point to the importance of mucosa $\operatorname{IgA}$ in the body defense system.

The authors declare no conflict of interest.

\section{References}

1. Corthésy B (2007): Roundtrip ticket for secretory IgA: role in mucosal homeostasis? J Immunol 178: 27-32.

2. Mestecky J, Russell MW (1997): Mucosal immunoglobulins and their contribution to defence mechanisms: an overview. Biochem Soc Trans 25: 457-462.

3. Mucosal immune defense: immunoglobulin A. Edited by Kaetzel CS, 2007.

4. Fagarasan S, Honjo T (2003): Intestinal IgA synthesis: regulation of front-line body defenses. Nat Rev Immunology 3 : 63-72.

5. Domínguez O, Giner MT, Alsina L, et al. (2012): Clinical phenotypes associated with selective IgA deficiency: a review of 330 cases and a proposed follow-up protocol. An Pediatr (Barc) 76: 261-267.

6. Ammann AJ, Hong R (1971): Selective IgA deficiency: presentation of 30 cases and a review of the literature. Medicine (Baltimore) 50: 223-236.

7. Latiff AH, Kerr MA (2007): The clinical significance of immunoglobulin A deficiency. Ann Clin Biochem 44: 131-139.

8. Sacks GS, Kudsk KA. Amino acids to support gut function and morphology. In: Metabolic and therapeutic aspects of amino acids in clinical nutrition. $2^{\text {nd }}$ ed. Cynober LA (ed.). CRC Press, 2003.

9. Zhu HL, Liu YL, Xie XL, et al. (2012): Effect of L-arginine on intestinal mucosal immune barrier function in weaned pigs after Escherichia coli LPS challenge. Innate Immun 19: 242-252.

10. Maggini S, Wintergerst ES, Beveridge S, Hornig DH (2007): Selected vitamins and trace elements support immune function by strengthening epithelial barriers and cellular and humoral immune responses. Br J Nutr 1: 29-35.

11. Cunningham-Rundles S (2001): Nutrition and the mucosal immune system. Curr Opin Gastroenterol 17: 171-176.

12. Winchurch RA, Togo J, Adler WH (1988): Supplemental zinc restores antibody formation in cultures of aged spleen cells. 
III. Impairment of II-2-mediated re-sponses. Clin Immunol Immunopathol 49: 215-222.

13. Aukrust P, Müller F, Ueland T, et al. (2000): Decreased vitamin A levels in common variable immunodeficiency: vitamin A supplementation in vivo enhances immunoglobulin production and down regulates inflammatory responses. Eur J Clin Invest 30: 252-259.

14. Park CK, Ishimi Y, Ohmura M, et al. (1997): Vitamin A and carotenoids stimulate differentiation of mouse osteoblastic cells. J Nutr Sci Vitaminol 43: 281-296.

15. Lander RL, Enkhjargal T, Batjargal J, et al. (2008): Multiple micronutrient deficiencies persist during early childhood in Mongolia. Asia Pac J Clin Nutr 17: 429-440.

16. Dijkhuizen MA, Wieringa FT, West CE, et al. (2001): Concurrent micronutrient deficiencies in lactating mothers and their infants in Indonesia. Am J Clin Nutr 73: 786-791.

17. Thurlow RA, Winichagoon P, Pongcharoen T, et al. (2006): Risk of zinc, iodine and other micronutrient deficiencies among school children in North East Thailand. Eur J Clin Nutr 60: 623-632.

18. Cameron C, Dallaire F, Vézina C, et al. (2008): Neonatal vitamin A deficiency and its impact on acute respiratory infections among preschool Inuit children. Can J Public Health 99: 102-106.

19. Penny ME, Peerson JM, Marin RM, et al. (1999): Randomized, community-based trial of the effect of zinc supplementation, with and without other micronutrients, on the duration of persistent childhood diarrhea in Lima, Peru. J Pediatr 135: 208-217.

20. Christian P, West KP Jr (1998): Interactions between zinc and vitamin A: an update. Am J Clin Nutr 68: 435-441.

21. Zhong W, McClain CJ, Cave M, et al. (2010): The role of zinc deficiency in alcohol-induced intestinal barrier dysfunction. Am J Physiol Gastrointest Liver Physiol 298: G625-633.

22. Elmes ME, Jones JG (1979): Ultrastructural changes in the small intestine of $\mathrm{Zn}$ deficient rats. J Pathol 130: 37-43.

23. Kassu A, Yabutani T, Mahmud ZH, et al. (2006): Alterations in serum levels of trace elements in tuberculosis and HIV infections. Eur J Clin Nutr 60: 580-586.

24. Kheirvari S, Uezu K, Sakai T, et al. (2006): Increased nerve growth factor by zinc supplementation with concurrent vitamin A deficiency does not improve memory performance in mice. J Nutr Sci Vitaminol 52: 421-427.

25. Prasad AS (2009): Zinc: role in immunity, oxidative stress and chronic inflammation. Curr Opin Clin Nutr Metab Care 12: 646-652.

26. Bao B, Prasad AS, Beck FW, et al. (2008): Zinc supplementation decreases oxidative stress, incidence of infection, and generation of inflammatory cytokines in sickle cell disease patients. Transl Res 152: 67-80.

27. Golden MH, Jackson AA, Golden BE (1977): Effect of zinc on thymus of recently malnourished children. Lancet 2 : 10571059.

28. Fraker PJ, King LE, Laakko T, Vollmer TL (2000): The dynamic link between the integrity of the immune system and zinc status. J Nutr 130: 1399S-1406S.

29. Bessler H, Wyshelesky G, Osovsky M, et al. (2007): A comparison of the effect of vitamin A on cytokine secretion by mononuclear cells of preterm newborns and adults. Neonatology 91: 196-202.

30. Jing MY, Sun JY, Wang JF (2008): The effect of peripheral administration of zinc on food intake in rats fed $\mathrm{Zn}$-adequate or Zn-deficient diets. Biol Trace Elem Res 124: 144-156.
31. Gaetke LM, Frederich RC, Oz HS, McClain CJ (2002): Decreased food intake rather than zinc deficiency is associated with changes in plasma leptin, metabolic rate, and activity levels in zinc deficient rats (small star, filled). J Nutr Biochem 13: 237-244.

32. Kwun IS, Cho YE, Lomeda RA, et al. (2007): Marginal zinc deficiency in rats decreases leptin expression independently of food in-take and corticotrophin-releasing hormone in relation to food intake. Br J Nutr 98: 485-489.

33. Mallo F, Lamas JA, Casanueva FF, Dieguez C (1992): Effect of retinoic acid deficiency on in vivo and in vitro $\mathrm{GH}$ responses to GHRH in male rats. Neuroendocrinology 55: 642-647.

34. Breen JJ, Matsuura T, Ross AC, Gurr JA (1995): Regulation of thyroidstimulating hormone subunit and growth hormone messenger ribonucleic acid levels in the rat: effect of vitamin A status. Endocrinology 136: 543-549.

35. Ghenimi N, Beauvieux MC, Biran M, et al. (2009): Vitamin A deficiency in rats induces anatomic and metabolic changes comparable with those of neurodegenerative disorders. J Nutr 139: 696-702.

36. Sagazio A, Piantedosi R, Alba M, et al. (2007): Vitamin A deficiency does not influence longitudinal growth in mice. $\mathrm{Nu}$ trition 23: 483-488.

37. Reifen R, Nur T, Ghebermeskel K, et al. (2002): Vitamin A deficiency exacerbates inflammation in a rat model of colitis through activation of nuclear factor-kappaB and collagen formation. J Nutr 132: 2743-2747.

38. Golub MS, Gershwin ME, Hurley LS, et al. (1984): Studies of marginal zinc deprivation in rhesus monkeys. IV. Growth of infants in the first year. Am J Clin Nutr 40: 1192-1202.

39. Haynes DC, Golub MS, Gershwin ME, et al. (1987): Longterm marginal zinc deprivation in rhesus monkeys. I. Influence on adult female breeders prior to conception. Am J Clin Nutr 45: 1492-1502.

40. Elmes ME, Jones JG (1979): Ultrastructural changes in the small intestine of Zn deficient rats. J Pathol 130: 37-43.

41. Southon S, Livesey G, Gee JM, Johnson IT (1985): Intestinal cellular proliferation and protein synthesis in $\mathrm{Zn}$-deficient rats. Brit J Nutr 53: 595-603.

42. Vallee BL, Falchuk KH (1993): The biochemical basis of Zn. Physiol Rev 73: 79-118.

43. Park CK, Ishimi Y, Ohmura M, et al. (1997): Vitamin A and carotenoids stimulate differentiation of mouse osteoblastic cells. J Nutr Sci Vitaminol 43: 281-296.

44. Yang Y, Yuan Y, Tao Y, Wang W (2011): Effects of vitamin A deficiency on mucosal immunity and response to intestinal infection in rats. Nutrition 27: 227-232.

45. Wiedermann U, Hanson LA, Holmgren J, et al. (1993): Impaired mucosal antibody response to cholera toxin in vitamin A-deficient rats immunized with oral cholera vaccine. Infect Immun 61: 3952-3957.

46. Brandtzaeg P, Farstad IN (1999): The human mucosal B-cell system. In: Ogra PL, Mestecky J, Lamm ME (eds.). Mucosal Immunology. Academic Press, San Diego; 439-468.

47. Fagarasan S, Honjo T (2003): Intestinal IgA synthesis: regulation of front-line body defenses. Nat Rev Immunology 3: 63-72.

48. Brandtzaeg P, Pabst R (2004): Let's go mucosal: communication on slippery ground. Trends Immunol 25: 570-577.

49. Macpherson AJ, Slack E (2007): The functional interactions of commensal bacteria with intestinal secretory IgA. Curr Opin Gastroenterol 23: 673-678.

50. Heremans JF (1974): Immunoglobulin A. In: Sela M (ed.). The Antigens. Academic Press, San Diego; 365-522. 